\title{
PLURALISMO JURÍDICO E O DIREITO AMBIENTAL DO TRABALHO: O EQUILÍBRIO DA BALANÇA NO DIREITO PARA COMUNIDADES TRADICIONAIS QUILOMBOLAS PESQUEIRAS NO BRASIL: O CASO DE MARÉ, NO BRASIL
}

\author{
Ingrid Gil Sales Carvalho ${ }^{1}$ \\ Daniel Valério Martins ${ }^{2}$ \\ Juliete da Paixão Vidal ${ }^{3}$
}

\begin{abstract}
Resumo:
O objetivo deste artigo é analisar a comunidade quilombola tradicional de pescadores artesanais e marisqueiras de Ilha de Maré, no Brasil, e sua exclusão social, histórica, econômica e cultural, sob a perspectiva do pluralismo jurídico e do direito ambiental do trabalho, o que teria resultado em um processo de invisibilidade. Trata-se de estudo de caso realizado na Comunidade Tradicional Quilombola e Pesqueira de Ilha de Maré, localizada no Brasil, em que foram utilizadas técnicas qualitativas, como a entrevista semiestruturada e a observação participante, além da revisão bibliográfica e documental. Constatou-se que o perfil elitista da monocultura jurídica do Estado brasileiro não tem permitido ao Brasil enfrentar problemas de gestão ambiental, do trabalho artesão e das comunidades tradicionais de per si, principalmente devido aos ditames da ordem econômica neocapitalista globalizada dominante, que são diametralmente opostos às necessidades e interesses de comunidades tradicionais. Percebeu- se que, na prática, a Comunidade Tradicional Quilombola e Pesqueira de Maré não encontrou eco nas vozes que insistem em demonstrar a exploração de seu ecossistema, a marginalização de seu modo de vida e cultura e a invisibilidade dos conflitos socioambientais por que passa.
\end{abstract}

Palavras-chave: Comunidade Tradicional. Pesca Artesanal. Pluralismo Jurídico.

\section{LEGAL PLURALISM AND THE ENVIRONMENTAL LABOR LAW: THE BALANCE OF BALANCE IN THE RIGHT FOR TRADITIONAL QUILOMBOLAS FISHING COMMUNITIES IN BRAZIL: THE CASE OF MARÉ ISLAND, IN BRAZIL}

\begin{abstract}
:
The objective of this article is to analyze the traditional quilombola community of artisanal fishermen and shellfish gatherers in Maré Island, Brazil, and their social, historical, economic and cultural exclusion, from the perspective of legal pluralism and environmental labor law, which would have result in an invisibility process. This is a case study carried out in the
\end{abstract}

\footnotetext{
${ }^{1}$ Doutoranda em Estado e Governança Global pela Universidade de Salamanca-Espanha (USAL); Mestra em Antropologia Íbero-Americana pela USAL; Mestra em Saúde, Ambiente e Trabalho pela Universidade Federal da Bahia (UFBA); Bacharela em Direito pela Universidade Católica do Salvador (USAL); e Professora de Direito pela Universidade de Caratinga (UNEC); ingridgsales@gmail.com.

${ }^{2}$ Pós-Doutor pelo Instituto Histórico Geográfico de Santa Catarina (IHGSC); Doutor em Estudos LatinoAmericanos pela Universidade de Salamanca-Espanha (USAL); Doutor em Educação pela Universidade de Burgos-Espanha; Mestre em Antropologia Íbero-Americana pela USAL; Mestra em Cooperação Internacional pela USAL, Valladolid, León e Burgos; Bacharela em Direito pela Universidade Católica do Salvador (USAL); e Professor do Mestrado de Antropologia Íbero-Americana pela USAL; jjfadelino@ hotmail.com.

${ }^{3}$ Graduanda em Direito - Universidade Salgado de Oliveira (UNIVERSO); Pós-graduada em Estudos Culturais, História e Linguagens - Centro Universitário Jorge Amado (UNIJORGE); Licenciada em História - Faculdade de Tecnologia e Ciências (FTC); juliete.vidal@hotmail.com.
} 
Traditional Quilombola and Fishing Community of Maré Island, located in Brazil, in which qualitative techniques were used, such as semi-structured interviews and participant observation, in addition to the bibliographic and documentary review. It was found that the elitist profile of the legal monoculture of the Brazilian State has not allowed Brazil to face problems of environmental management, artisan work management and management of traditional communities per se, mainly due to the dictates of the globalized neo-capitalist economic order dominant, which are diametrically opposed to the needs and interests of traditional communities. It was noticed that, in practice, the Traditional Quilombola and Fishing Community of Maré Island did not find an echo in the voices that insist on demonstrating the exploitation of their ecosystem, the marginalization of their way of life and culture and the invisibility of the socioenvironmental conflicts that they are going through.

Keywords: Traditional Community. Artisanal fishing. Legal Pluralism.

\section{Introdução}

O pluralismo jurídico pode ser visto atualmente como uma teorização ideológica contrária à dominação, contrapondo-se, porém, à "pluralidade" de ordens jurídicas imbuídas da ideia ínclita presente em muitos dos defensores do pensamento do pluralismo clássico e propondo a formação de "um novo senso comum jurídico", que deve se orientar para o paradigma da concepção pós-moderna do direito, do que seja o Direito e do que é ter direito a ter direitos (TREVIZAN; LEÃO, 2014; SANTOS, 2013; WOLKMER, 2019).

Nesse sentido, não seria suficiente apenas reconhecer que coexistem várias ordens jurídicas distintas no mesmo espaço (território) e ao mesmo (tempo) regulamentando sujeitos e objetos do direito, aduzindo que o direito é produzido também por outras esferas sociais, porém, subordinando-se esse direito ao direito oficial estatal, que detém a "universalização da sanção", como inicialmente fora defendido e difundido por Santos (1988). Mais do que isso, o pluralismo jurídico aqui defendido é aquele que rompe com a ciência moderna do direito, é a "construção de uma teoria crítica do direito" com o "ideal" de Estado moderno democrático de direito em prol da insurgência, do reconhecimento, da emancipação e da possibilidade na práxis de ação de ordens jurídicas antes tidas apenas como inexistentes, após, como existentes, porém, ainda como subversivas ou submissas, para agora, na pós-modernidade, poderem ser consideradas existentes, reais, concretas, legais, legítimas, válidas e até, quem sabe, efetivas e eficazes (ZIBECHI, 2015; SANTOS, 2013; BARRETO, MARTINS e VIDAL, 2021).

Segundo Santos (1988), Ardila Amaya (2002) e Rios (2020), a pluralidade jurídica já começava a se insurgir e até se impor sem a autorização do sistema normativo legal estatal oficial, por vezes, com o exercício da violência física, pelas várias dinâmicas sociais e econômicas de regulação existentes, tais como: de comunidades tradicionais excluídas, como o 
caso de Ilha de Maré no Brasil, de comunidades completamente marginalizadas frente a omissão do poder estatal, como as favelas de grandes capitais do Brasil, como as do Rio de Janeiro, de Salvador e de São Paulo, de sociedades que emergem como resultado da ação de novos movimentos sociais por grupos vulneráveis, em razão da opção sexual, do gênero, cultura, e/ou da raça, e de casos que se apresentam em crises institucionais ou mais gravosas, de violência física e psicológica permanente, como por exemplo, o surgimento das Forças Armadas Revolucionárias da Colômbia ou dos Milicianos nas favelas do Rio de Janeiro.

Nesse sentido, já permeavam as análises dos conflitos socioambientais estudos que fizessem referências às pluralidades jurídicas ou sob a perspectiva do pluralismo jurídico. Segundo Martins (1989), o dimensionamento dos conflitos socioambientais possibilitou o surgimento de novos sujeitos sociais e de novos movimentos sociais, isto é, precisamente a ação política de grupos subalternos, excluídos, invisíveis, imbuídos de um sistema de direito alternativo próprio e auto regulatório. Dessa forma, Martins (1989) parecia, à época, prever o surgimento de sistemas jurídicos normativos próprios, oriundos de comunidades tradicionais extrativistas resistentes à cultura da pós-modernidade, quando aduzia que:

Além de constituírem uma organização social em que práticas, técnicas e conhecimentos baseiam-se nos costumes, frequentemente são as próprias comunidades que ditam as normas das relações socioambientais, isto é, as relações que os membros das comunidades estabelecem entre si ou com outros componentes do território que ocupam envolvendo questões ambientais. Tal situação arrepia ao poder judiciário do Estado. (MARTINS, 1989, p. 34).

Para Nicolau Junior (2005), a segurança jurídica, basilar do nosso sistema democrático de Direito, pós moderno, embasada na uniformidade de decisões emanadas do sistema normativo jurídico oficial estatal, que ganhou força com a promulgação do novo Código de Processo Civil de 2015 no Brasil e o seu Sistema de Precedentes Normativos (DIDIER JÚNIOR, 2017) nega a flexibilidade, a dinâmica das relações econômico-sociais, a realidade da existência e vivência do trabalhador informal, a factualidade do dano ambiental do cotidiano e da invisibilidade dos conflitos socioambientais ocasionados pelo mesmo e, a inevitável evolução ou, ao menos, transformação de uma sociedade e seus componentes, em decorrência das mudanças econômicas, culturais, sociais e políticas, implementadas, por exemplo, pelo surgimento de novas moedas, novas mercadorias de valores, o distanciamento social na modalidade presencial em troca do alinhamento social na modalidade digital, o advento de novos monopólios sobre o "bom" comportamento exigido quando da utilização das mídias digitais e, claro, como assuntos públicos e/ou governamentais passaram a ser recepcionados e tratados pela população em geral. 
Assim, o que se verifica na práxis é a emergência de reivindicações oriundas de comunidades tradicionais, quilombolas, pesqueiras artesanais, como a de Ilha de Maré no Brasil, em situações relativas a conflitos socioambientais, não levadas em consideração no passado, período de colonização e pós colonização do Brasil, relatado por sociólogos, antropólogos e historiadores (CAROSO et alii, 2011) e, nem no presente, uma vez que tais conflitos socioambientais, têm sido marginalizados pelo estado democrático de direito em suas diversas esferas de poderes, perpassando pelo poder executivo, com a omissão deliberada no que é pertinente à criação e execução de políticas públicas voltadas para Comunidades Tradicionais, bem como a mal sucedida administração quando se refere à proteção do meio ambiente natural/laboral, o legislativo, com a elaboração e aprovação de legislações e decretos que não se preocupam com o meio ambiente e o desenvolvimento sustentável do país, bem como permitem a marginalização e exclusão de culturas oriundas de Comunidades Tradicionais, até chegar ao judiciário que, ao aplicar o Sistema de Precedentes Normativos oriundos do Novo Código de Processo Civil, ou o singular Juspositivismo clássico, se esquece deliberadamente da busca pela "verdade real”, do que seja fazer "justiça”" (ZIBECHI, 2015).

É nesse sentido que um novo pluralismo jurídico ressurge, pleiteando novas dinâmicas, buscando precipuamente uma "criticidade ao próprio direito" (SANTOS, 2013), no intuito de que sejam atendidas as demandas de comunidades tradicionais como a de Maré, colocando por terra a simples possibilidade de, em um mesmo território, no mesmo período, existirem simultaneamente duas normativas, uma estatal e outra não oficial, mais do que isso, o que pretende este artigo é analisar o processo de invisibilidade que recai sobre uma comunidade quilombola tradicional de pescadores artesanais e marisqueiras no Brasil, a da Ilha de Maré, como resultado de sua exclusão social, histórica, econômica e cultural, isso sob a perspectiva do pluralismo jurídico e do direito ambiental do trabalho. Do pluralismo jurídico porque o monopólio jurídico estatal brasileiro sequer reconhece a existência e/ou validade do sistema jurídico normativo próprio da Ilha de Maré, perpetrado por sua Comunidade Tradicional Quilombola de Pescadores Artesanais (BARRETO; MARTINS; VIDAL, 2021) e do direito ambiental do trabalho, porquanto este se trata do único ramo do direito capaz de compreender como o meio ambiente natural afeta direta e indiretamente o meio ambiente de trabalho, e pela premissa de defesa de direitos não somente do meio ambiente natural, como também dos trabalhadores ali inseridos, sejam eles informais ou não, artesãos ou não, defendendo o "todo", um "sistema" e não promovendo a defesa de objetos separados a serem tutelados pelo direito (CARVALHO et alii, 2014). 
Assim sendo, o objetivo deste artigo é analisar a comunidade quilombola tradicional de pescadores artesanais e marisqueiras de Ilha de Maré, no Brasil, e sua exclusão social, histórica, econômica e cultural, sob a perspectiva do pluralismo jurídico e do direito ambiental do trabalho, o que teria resultado em um processo de invisibilidade.

\section{A defesa dos direitos das Comunidades Tradicionais no Brasil e o caso de Maré}

Comunidades Tradicionais são compreendidas como "grupos culturalmente diferenciados e que se reconhecem como tais", segundo o Decreto nº 6040/2007, em seu artigo $3^{\circ}$, inciso I, decreto este que instituiu a Política Nacional de Desenvolvimento Sustentável dos Povos e Comunidades Tradicionais no Brasil. Também, segundo o decreto, as Comunidades Tradicionais "possuem formas próprias de organização social", ocupando e usando "territórios e recursos naturais como condição para sua reprodução cultural, social, religiosa, ancestral e econômica", além de utilizarem "conhecimentos, inovações e práticas gerados e transmitidos pela tradição".

Maré é enquadrada como Comunidade Tradicional porquanto seus moradores praticam majoritariamente a atividade de pesca artesanal para homens e a de mariscagem para mulheres, transmitindo o conhecer-fazer pela oralidade, passada de geração a geração, e pela prática espelhamento, quando bebês desde cedo acompanham suas mães na atividade da mariscagem, e a partir dos doze aos catorze anos de idade, os meninos são enviados para a prática da pesca artesanal com os pais e as meninas permanecem na mariscagem com a mães (CARVALHO, 2013). Também, Maré é enquadrada como Comunidade Tradicional porque detém comunidades quilombolas ou resquícios de quilombos, o que fora comprovado pela Fundação Cultural Palmares (FCP) que já certificou duas comunidades de Maré como quilombolas, atendendo ao Decreto $n^{\circ} 4.887 / 2003$ e a Portaria da FCP nº 98/2007. É válido ressaltar que ser quilombo trata-se de um direito grupal à autodefinição preconizado pela Convenção no 169 da Organização Internacional do Trabalho (OIT), e de como se percebe a história resultante da formação do quilombo e as maneiras como dela se apropria desde a sua origem (CHAGAS, 2001).

A Comunidade Tradicional de Maré já enfrentou e permanece enfrentando diversos danos ambientais, desde a instalação na Baía de Aratu, nas décadas de 1950 e 1960, do Porto de Aratu e da antiga Companhia Industrial de Aratu, atualmente denominado de Comitê de Fomento Industrial de Camaçari, uma vez que há tempos relatam a diminuição do quantitativo e da qualidade de mariscos, crustáceos e peixes na região (CARVALHO, 2013), e ainda a contaminação desses, como a presença de óleo cru em determinados peixes e mariscos, o gosto 
alterado e o mau cheiro, ambos presentes nos mariscos, crustáceos e peixes da Baía de Aratu (CARVALHO et alii, 2014) além de odores que ardem e queimam os olhos e narinas em certos períodos do dia, em Ilha de Maré, especialmente em crianças e idosos, toda vez que aparece uma fumaça amarela deslocada pelos ventos da região industrializada de Aratu (RÊGO et alii, 2018; RÊGO et alii, 2019). São diversas queixas e reclamações realizadas pela Comunidade Tradicional de Maré desde a ocorrência do processo de industrialização da Baía de Aratu, que está localizada a apenas $19 \mathrm{~km}$ de Ilha de Maré.

Tais danos ambientais levaram os pescadores artesanais e as marisqueiras de Ilha de Maré a protestarem no Porto de Aratu, a concederem entrevistas nas quais acusavam empresários, governo do Estado da Bahia e governo do Município de Salvador pela omissão e ineficácia, além do reclame pela atuação dos órgãos ambientais de fiscalização e/ou proteção, que permaneciam inertes, além do conclame pela atuação mais combativa do Ministério Público e da Defensoria Pública (CARVALHO, 2013; RÊGO et alii, 2019). Dessa forma, percebeu-se que a comunidade tradicional sozinha, de per si, por seus métodos próprios, não seria capaz de solucionar problemas dessa envergadura, conflitos sócio ambientais estabelecidos com pessoas jurídicas de direito privado de elevado poderio econômico e órgãos públicos oficiais governamentais, nos quais, ambos, baseiam suas tomadas de decisões fundadas no capitalismo neoliberal globalizado tecnológico, ou seja, utilizando-se do discurso de que "a produção não pode parar porque o prejuízo seria imenso", uma vez que a comunidade tradicional representa para esses "o passado", “o velho", "o retrógrado", um "atraso" em relação à evolução civilizatória "nítida" e "imprescindível” da sociedade pós-moderna.

Nessa senda, comunidades tradicionais quilombolas como a de Ilha de Maré no Brasil, que praticam majoritariamente a pesca artesanal e a mariscagem extrativista, como modos de vida, de exercício laboral, e de prática cultural, totalmente dependentes da salubridade do meio ambiente natural e laboral (CARVALHO, 2013; CARVALHO et alii, 2014), apresentam condição desfavorável frente aos agentes externos à comunidade, com poderio econômico de cunho inestimavelmente superior e interesses completamente diversos, quando não antagônicos, em relação aos pleitos dessas comunidades, que são dependentes do ecossistema local ecologicamente saudável, equilibrado e sustentável.

Dessa forma, defende Vieira (2006), que ganha ainda mais relevância no cenário da pósmodernidade perceber qual o tratamento legal ofertado pelo sistema jurídico normativo oficial estatal para comunidades tradicionais, quando se tem em vista que a manutenção dessas está atrelada à existência de um arcabouço jurídico que as proteja efetivamente, bem como promova a outorga de titularidade de seus territórios já ocupados anteriormente e que garanta a 
identificação e a reprodução do grupo vulnerável culturalmente, não permitindo que o meio ambiente natural e laboral dessas comunidades seja atingido por contaminantes, poluentes, gerando um desequilíbrio no ecossistema local na práxis, ou que haja uma recuperação do meio ambiente, quando já degradado.

\section{$2 \mathrm{O}$ direito que é praticado na Comunidade Tradicional de Ilha de Maré}

Entende Capucci (2016) que as normas de coesão e organização social criadas pelos povos e comunidades tradicionais, isto é, o sistema normativo próprio de cada comunidade não subsistiriam frente aos seus opositores, em se tratando de conflitos socioambientais, sem o arcabouço jurídico já existente atualmente no Brasil, como o Direito Constitucional e o Direito Ambiental, que buscam proteger, ainda que teoricamente, tais comunidades compreendidas como tradicionais, como quilombolas ou remanescentes de quilombos, seus territórios, modos de produção e reprodução artesanal e estilos de vida de não acumulação de capital e de bens materiais, e de não consumismo exacerbado, pregando por vezes o reducionismo.

Contudo, o Direito Ambiental do Trabalho, apesar de ainda em formação no Brasil (CARVALHO et alii, 2014), constitui-se no ramo da Ciência Jurídica, que tem como precípuo basilar não apenas a preservação do meio ambiente de per si, a fauna, a flora, mas também a proteção do ser humano que labora nesse meio ambiente, que é totalmente dependente do mesmo e do equilíbrio entre o meio ambiente natural e o ser humano que labora artesanalmente e extrai os insumos para a realização do seu trabalho diretamente do meio ambiente, no qual está inserido.

Por décadas os habitantes de Maré viveram de modo distanciado, quase que isolados do centro urbano de Salvador, o que somente pôde acontecer em razão da formação de Maré, seu contexto histórico e do seu contexto geográfico. Ilha de Maré formou-se por meio de uma rede de solidariedade com a prática do escambo entre escravos fugidos que conseguiam sobreviver à travessia nadando entre Salvador e Maré, de negros libertos e refugiados que seguiam de pequenas embarcações do Porto de Mataripe de Salvador até Maré e que encontravam na Ilha um modo de sobrevivência econômico-social e cultural, além da prática comum da pesca artesanal, da mariscagem, do plantio de pequenos insumos e da criação de pequenos rebanhos de animais, os moradores perpetuaram práticas religiosas afro-brasileiras, como o sincretismo religioso, a dança e a música afros, gerando o que denominamos atualmente de Comunidades Quilombolas e/ou Remanescentes de Quilombos (CAROSO et alii., 2011; CARVALHO, 2013). 
Nesse sentido, restou perceptível que a Comunidade Tradicional Pesqueira Artesã de Maré faz uso internamente das normas socioambientais estatais oficiais vigentes, conhecidas, aceitas e praticadas pelos Moradores de Maré (BARRETO; MARTINS; VIDAL, 2021) como normas relacionadas, principalmente, aos direitos difusos e coletivos, como a proteção integral ao meio ambiente natural e de que todos têm direito a um meio ambiente ecologicamente equilibrado e saudável, disciplinados em diversas legislações, com conteúdo ambiental e/ou social no Brasil, como a Constituição Federal de 1988, a Política Nacional dos Povos e Comunidades Tradicionais, a Lei de Acesso ao Patrimônio Genético e ao Conhecimento Tradicional Associado, o Estatuto da Igualdade Racial, o Sistema Nacional de Unidades de Conservação e outros.

Além da Comunidade Tradicional de Maré promover internamente o reconhecimento e a validação do Estatuto do Idoso, do Estatuto da Pessoa com Deficiência e na esfera penal até da Lei Maria da Penha (que busca proteger mulheres em situação de violência doméstica), e também de diferentes regulamentações previdenciárias, como a necessidade de contribuição para o Regime Geral de Previdência Social do Instituto Nacional do Seguro Social (INSS), entre outras, encontrando dificuldades de implementação no que diz respeito, especificamente, ao Estatuto da Criança e do Adolescente, como já havia sido observado por Pena (2011) e Freitas et alii (2012), uma vez que, comumente, crianças ainda acompanham as mães desde cedo na atividade da mariscagem e os adolescentes começam precocemente o desenvolvimento de atividades que se enquadram como penosas dentro da pesca artesanal e da mariscagem, ajudando os pais e entes familiares como mais uma força de trabalho e, também por ser compreendida internamente, tal força de trabalho precoce pela Comunidade, como forma de transmitir desde cedo a cultura milenar da pesca artesanal e da mariscagem para os descendentes (PENA, 2011; FREITAS et alii, 2012 apud CARVALHO, 2013).

Evidenciou-se que normas estatais oficiais vigentes do Estado brasileiro, socioambientais e de outras searas, são passadas pelas lideranças locais, apoiadas e assistidas tecnicamente por advogados voluntários e por advogados de organizações não governamentais, para a comunidade tradicional por meio de reuniões, realização de cursos e oficinas, assembleias, que são realizados pela Associação de Moradores de Maré e pela Colônia de Pescadores de Maré, além da participação dos líderes comunitários de Maré em eventos científicos, como congressos, seminários e simpósios locais, regionais e nacionais, que versam sobre a temática de conflitos socioambientais, danos ambientais, e/ou de Comunidades Tradicionais, e/ou de Comunidades Quilombolas, e/ou que tratam sobre a Pesca Artesanal no Brasil, entres outros instrumentos. Ressaltam Trevizan e Leão (2014) que o atendimento às 
normas oficiais estatais se trata quase de uma "catequese" normativa do mundo jurídico estatal oficial que é imposta às Comunidades Tradicionais, sem que haja qualquer observância, peculiaridade ou exceção a ser evidenciada:

\begin{abstract}
Percebeu-se que o conhecimento dessa legislação socioambiental oficial pelos moradores, assim como a sua observância, tem uma função inclusiva, uma vez que facilita o acesso às políticas públicas ambientais, pois a comunidade torna-se melhor conhecedora dos seus direitos, e uma função psicoeducativa, já que os moradores passam a censurar uns aos outros quando essas normas são descumpridas. No entanto, não pode passar despercebida que essa função inclusiva e educativa resultante do conhecimento e cumprimento da legislação oficial é produto do próprio processo de intervenção da oficialidade no território das comunidades, mediante uma catequização com normas de proteção ao meio ambiente natural, criadas e impostas, na maioria das vezes de cima para baixo, sem o propósito de proteger a vida e respeitar os costumes de comunidades como a aqui analisada, que se desenvolveram por várias gerações, historicamente esquecidas pela legislação do Estado dominador, mas que sempre dependeram do uso dos recursos da natureza para sua sobrevivência. $\mathrm{O}$ acesso às políticas públicas, de certa forma, torna-se uma dádiva do Estado, condicionada ao cumprimento das normas por ele estabelecidas. (TREVIZAN; LEÃO, 2014, p. 544-545).
\end{abstract}

Nesse sentido, normas socioambientais oficiais, criadas e impostas pelo Estado moderno democrático de direito brasileiro, especificamente dirigidas a habitantes de comunidades tradicionais, como a de Maré, ou seja, normas que regulamentam a atividade pesqueira artesanal, como a que cria os períodos de defeso de exploração do pescado (Lei n ${ }^{\circ}$ 10.779/2003), dentre outras normas, de cunho civil e até penal, são observadas na maioria das vezes pela Comunidade Tradicional de Maré. Ademais, o conhecimento e a prática acerca dessas normas são transmitidos ainda de pescador para futuro pescador, de marisqueira para futura marisqueira. Nesse sentido, crianças e adolescentes já iniciados nas atividades pesqueiras e de mariscagem são informados a despeito da existência dessas normas estatais oficiais externas, mas que também devem ser respeitadas e cumpridas internamente.

Por certo, essa inserção ou relação estabelecida com o sistema jurídico oficial estatal brasileiro também ocorre quando a Comunidade Tradicional de Maré pleiteia em seu favor, para atuar na resolução dos conflitos socioambientais, a prestação positiva por agentes públicos, entes governamentais de fiscalização, como o Instituto Brasileiro do Meio Ambiente e dos Recursos Naturais Renováveis - IBAMA, o Instituto do Meio Ambiente e Recursos Hídricos INEMA, o Instituto Nacional de Colonização e Reforma Agrária - INCRA, a Secretaria de Patrimônio da União - SPU, o Ministério Público Estadual da Bahia, a Defensoria Pública do Estado da Bahia e da União, e do próprio Estado Oficial, como o Município de Salvador e suas Secretarias de Saúde e Meio Ambiente e o Estado da Bahia, com suas Secretarias de Saúde e Meio Ambiente. 
A resolução dos conflitos socioambientais, por meio de mecanismos com características de oficialidade, como a jurisdição, e as heterocomposições com órgãos administrativos são importantes por conferir maior segurança jurídica aos moradores. A força e a certeza de uma sentença emanada por um órgão pertencente à estrutura oficial do governo tranquilizariam os moradores no sentido de que esta decisão é dotada de coercibilidade. (TREVIZAN; LEÃO, 2014, p. 545).

Nessa esteira, Trevizan e Leão (2014, p. 544) defendem que comunidades tradicionais deveriam poder encontrar no Estado juiz (poder jurisdicional estatal oficial) "um importante aliado e um instrumento de resistência contra a invasão de atores exógenos" que possam modificar o modelo e a visão de mundo das comunidades tradicionais, que, por sua vez, são dependentes de uma relação simbiótica entre sociedade e natureza particular e diferenciada. $\mathrm{Na}$ práxis, as comunidades tradicionais não têm tido seus direitos resguardados seja pelos poderes executivo e legislativo, seja pelo poder judiciário. Ao invés disso, o poder normativo estatal oficial, aliado ao sistema econômico neoliberal globalizado, tem pilhado ou permitido o esfacelamento de Comunidades Tradicionais no Brasil.

\section{0 direito local da Comunidade Tradicional de Maré e o direito estatal oficial}

Destacou-se, portanto que o direito consuetudinário, de origem local, ainda comum em Comunidades Tradicionais no Brasil mostra-se importante, pois permite maior adequação das normas socioambientais às reais necessidades da comunidade. A esse respeito, Dworking (2002, p. 14) argumenta que o direito, aqui tratando-se especificamente do direito consuetudinário existente na Comunidade Tradicional de Maré, "vai além de um sistema de regras baseado num teste fundamental", assim, a normatização local é importante para que a própria Comunidade regulamente e regule o uso dos recursos naturais no extrativismo, estabelecendo seus padrões de sustentabilidade.

Por sua vez, o inverso não ocorre, isto é, o Estado moderno democrático de direito no Brasil, fazendo uso da "realidade simbólica do direito" como defendida por Bourdieu (2007) segue ocupando no século XXI, como bem nos demonstra Santos (2009), o "status de detentor do monopólio jurídico", o único a estabelecer e estar autorizado a difundir "o que é o direito no Brasil". Assim, a batalha pela produção "da rede de significados no direito" se tornou totalmente desigual, tornando ilusória a possibilidade do direito local de Comunidades Tradicionais brasileiras ser reconhecido como um direito interno válido e regular para o Estado democrático de direito brasileiro (ANDRADE, 2015). Isto posto, é válido afirmar que não existe no Brasil um equilíbrio da balança na produção do sistema jurídico normativo oficial 
estatal, posto que esse derroca qualquer outro direito interno inserto em uma Comunidade Tradicional.

Por certo, comunidades tradicionais quilombolas pesqueiras no Brasil, assim como os demais grupos étnicos vulneráveis, estão sempre em desvantagem, uma vez que, por detrás, ou mesmo, ao lado do Estado democrático de direito, segue assente o sistema econômico capitalista de cunho neoliberal, globalizado e tecnológico, cuja premissa de consumo exasperado para todos e de acumulação de bens, mercadorias, serviços e moedas para poucos em detrimento da escassez generalizada de serviços básicos comuns para muitos, compreende a existência e resistência das comunidades tradicionais como um movimento destinado à debilidade e até aniquilação. Nessa mesma senda compreende-se que

[...] o direito não só serve para resolver conflitos, senão também para criar "realidade simbólica" produzida e significada pelo humano enquanto "animal simbólico", para usar a expressão de Cassirer (1968). Talvez se entenda melhor isto se nos interrogamos: Como se pode entender que um casal de indivíduos de sexo oposto ao realizar um formalismo jurídico, deixem de ser percebidos como dois indivíduos e se convertam num "casal"? Como um indivíduo que cumpre com certos requisitos formais deixa de ser tal e se converte, para os olhos de uma comunidade, em "cidadão"? ou como, através de algumas convenções legais, se pode considerar a um sujeito ou bem um ladrão ou bem um cleptómano? etcétera. Esta é precisamente "a magia" do direito, estatal neste caso, a de transmitir algumas pautas e que os indivíduos sejam capazes de connotar esses símbolos e os relacionar com outros para os converter em "realidade". É por esta razão que, desde meu ponto de vista, para fazer um uso contra hegemónico do direito, e especialmente do direito estatal, não é suficiente um "simples" distanciamiento voluntarista de usar a este para uma causa justa ou na protecção dos sectores sociais excluídos; senão que se requer uma tomada de consciência mais radical que implica o conhecimento das consequências do uso do direito e por tanto o manejo mais prudencial de uma ferramenta que ainda que permita tomar algumas vantagens dentro do sistema só se fazem possíveis, precisamente, pela preeminência deste sistema de dominação simbólica. (ANDRADE, 2015, p. 289).

Segundo Porto, Pacheco e Leroy (2013), o mapa de justiça ambiental descreve como conflitos socioambientais relativos às comunidades tradicionais quilombolas residentes em Ilha de Maré, os seguintes:

Luta contra as práticas racistas;

Alteração do regime tradicional de uso e ocupação do território; Irregularidades ambientais derivadas da falta de licenciamento do porto;

Falta de atuação dos órgãos ambientais;

Ausência de estudos relacionados aos riscos a que a população local estaria exposta face à poluição provocada pelas indústrias químicas ali instaladas;

Impactos ambientais provocados pela dragagem realizada a fim de aumentar a competitividade do porto, processo que estaria provocando a mortandade de peixes e prejudicando os pescadores, além do risco à saúde dos moradores representado pela suspensão de sedimentos do fundo da baía, contaminados por resíduos tóxicos; 
Falta/irregularidade na demarcação de território tradicional. São mais de 500 famílias aguardando o "reconhecimento de sua identidade étnica e pela demarcação de seu território tradicional." (LIS/ICICT/Fiocruz, 2014, p. 13).

Está-se, portanto, falando de um desequilíbrio, uma desigualdade descomunal que ocorre entre o direito consuetudinário produzido pela Comunidade Tradicional de Maré, no Brasil, e o sistema jurídico normativo oficial estatal que procura regular a tudo e a todos, impondo-lhes o "ideal" da era pós-moderna, o "se enquadre", o "se adapte", o "se encaixe", caso contrário, a Comunidade Tradicional de Maré, que já sofre as consequências da exploração, pilhagem, marginalização e invisibilidade, corre um sério risco de ser "extirpada" (CHAMY, 2004; FUCHS, 2013; MARCONDES; RAIMUNDO, 2019). Por certo, mais uma vez, está havendo o predomínio dos ditames econômicos neoliberais, de cunho individualizado, que hegemoniza o capitalismo globalizado em face de tudo e de todos (BOURDIEU, 2001, 2003, 2007).

\section{Material e Métodos}

Nesse sentido, utilizamos diversos métodos combinados, como a pesquisa bibliográfica e a pesquisa documental. Foi importante a coleta de dados da pesquisa, bem como fazer uso de documentos públicos, tais como pareceres, relatórios, anuários, regulamentos, instruções normativas, leis, decretos federais e projetos desenvolvidos pelo IBAMA, INCRA, INSS e INEMA. Dados estatísticos para compreensão de quem seja o morador da Ilha de Maré por meio dos dados do Instituto Brasileiro de Geografia e Estatística (IBGE) e o Mapa de Conflitos gerenciado pela Escola Nacional de Saúde Pública (ENSP) que trata de informações históricas e documentadas sobre os conflitos sócios ambientais vivenciados pela Comunidade de Maré.

Também foi relevante investigar as legislações editadas pela Câmara Municipal de Salvador, principalmente em relação ao Plano Diretor de Desenvolvimento Urbano (PDDU) de Salvador, dos anos 2008 e 2016, as portarias e decretos expedidos pelo Chefe do Poder Executivo de Salvador na forma como tratam Ilha de Maré quanto ao seu enquadramento no espaço urbano, ou seja, se a Ilha recebeu o tratamento de uma Área de Proteção Ambiental, de uma Reserva Ecológica Florestal, de uma Reserva Extrativista ou outra, além das leis emanadas pela Assembleia Legislativa Estadual da Bahia que também estão aptas a legislarem sobre matéria concorrente do meio ambiente e, por fim, a regulamentação sobre a ampliação e reforma da Companhia Portuária do Estado da Bahia (CODEBA) pelo Governo do Estado da Bahia, tendo sido utilizadas as seguintes palavras-chave: Comunidade Tradicional, Pescador 
Artesanal, Pesca Artesanal, Pluralidade Jurídica, Direito, Direito Ambiental do Trabalho, Direito Ambiental, Quilombola e Quilombo.

Utilizou-se como método qualitativo, a entrevista semiestruturada, a qual foi realizada por meio da utilização de um roteiro de tópicos relacionados ao problema, com liberdade do entrevistador para elaborar outras questões que considerasse relevantes para a análise do tema. Tendo sido entrevistado ao todo oito marisqueiras ou ex-marisqueiras e quatro pescadores artesanais ou ex-pescadores artesanais da Ilha da Maré. Tendo ainda sido aplicado um teste piloto da entrevista semiestruturada com uma marisqueira e com um pescador artesanal da Ilha da Maré, conforme recomendação de Minayo (2002). Ainda como método qualitativo, fez-se uso da observação participante que perdurou ao todo por seis meses em Ilha de Maré, nas Comunidades Tradicionais de Bananeiras e de Praia Grande, de julho a dezembro de 2019.

Para Oliveira (2010), uma abordagem que leva em conta as três dimensões temáticas dos conflitos sócios ambientais (direitos, interesses e reconhecimento), e que incorpora a análise das três dimensões contextuais que dão sentido ao que realmente está acontecendo na práxis, poderia permitir uma compreensão mais ampla e profunda dos conflitos, reivindicações de direitos e procedimentos. Nesse sentido, o estudo de caso realizado em Maré, enquanto método qualitativo, atende às dimensões cultural, situacional e contextual, isso porque, segundo Yin (2010), o estudo de caso visa compreender fenômenos sociais e ambientais complexos, em que múltiplas variáveis intervêm de modo simultâneo, isso quer dizer que o estudo de fenômenos contemporâneos em contrapartida a fenômenos históricos exige por vezes do investigador um olhar de pesquisador e uma participação de sujeito no próprio contexto onde o fenômeno vem acontecendo.

Dessa forma, Ilha de Maré fora eleita para o presente estudo de caso porquanto detém uma vasta publicação quanto à dimensão cultural que permeia seus moradores (CAROSO et alii, 2011; FREITAS et alii, 2012; CARVALHO, 2013), além da dimensão situacional, quanto aos efeitos e consequências da poluição e danos ambientais causados ao ecossistema de Maré, sua fauna, flora, mar, manguezais, animais marinhos e moradores de Maré, que já haviam sido relatados em diversas investigações científicas realizadas e/ou artigos publicados nacional e internacionalmente a esse respeito desde os anos 1970 no Brasil por investigadores da Universidade Federal da Bahia (CARVALHO, 2013; CARVALHO et alii, 2014; REGO; LARREA-KILLINGER; BARRETO, 2018; RÊGO et alii, 2018; RÊGO et alii, 2019; HATJE, 2011; HATJE et alii, 2019; PENA et alii, 2019; SILVA, 2018) e, no que se refere à dimensão contextual, os estudos que têm sido recentemente discutidos ao correlacionarem a exclusão, a opressão, a invisibilidade de Ilha de Maré, sua Comunidade Tradicional, seus moradores, seus 
pescadores artesanais e suas marisqueiras, ao sistema econômico capitalista neoliberal globalizado, à ineficiência na vigilância de saúde do trabalhador artesão, à omissão do Estado nos níveis municipal, estadual e federal e seus órgãos de fiscalização e planejamento ambiental, à pilhagem perpetrada pelo manto do estado democrático de direito sob a premissa de que as Comunidade Tradicionais precisam se adaptar às novas realidades (PENA et alii, 2019; RÊGO et alii, 2019; RIOS, 2020; SALES; VIDAL, 2020, BARRETO; MARTINS; VIDAL, 2021) e tantos outros.

\section{Resultados e Discussão}

Evidenciou-se que, ao atribuir ao direito ambiental do trabalho à defesa e promoção do meio ambiente de trabalho saudável de pescadores artesanais e marisqueiras de Maré, embasado nos princípios norteadores, na sistemática do Direito Ambiental do Brasil e de todo o seu arcabouço jurídico, agora voltados eminentemente para a defesa do meio ambiente natural e laboral saudável, equilibrado e sustentável, assim como dos pescadores artesanais e marisqueiras ali inseridos, que de fato, esse novo campo do saber, formando-se recentemente como disciplina jurídica, poderia tentar efetivar o direito ao meio ambiente de trabalho sadio da Comunidade Tradicional de Maré. O ser humano é indissociável da natureza e vice-versa, estando ambos interconectados e inter-relacionados (CARVALHO, 2013, CARVALHO et alii, 2014).

Autores como Rocha $(2002,2018)$ e Carvalho et alii (2014) concluíram pelo direito ambiental do trabalho se tratar do único campo do saber jurídico possivelmente capaz de promover o direito ao meio ambiente natural/laboral saudável, cuja insalubridade afeta direta e indiretamente a natureza, o pescador artesão e a marisqueira daquele habitat. Nesse sentido expôs Carvalho (2013):

Acredita-se que a salvaguarda dos direitos preconizados por pescadores artesanais e marisqueiras de Maré como o direito à saúde, à vida e ao trabalho estão intimamente interligados com o meio ambiente de trabalho sadio, seguro, equilibrado e sustentável, que se entende ser mais bem promovido e garantido pelo Direito Ambiental do Trabalho, não pelo Direito do Trabalho ou pelo Direito Ambiental, já que o primeiro, embora seja emergente na área do saber jurídico, outrossim, possui como premissa precípua o meio ambiente de trabalho sadio e a saúde dos trabalhadores nesse meio. É o meio ambiente de trabalho que agrega pescadores e marisqueiras de Ilha de Maré e o Direito Ambiental do Trabalho no Brasil em um único objetivo, o de promover, defender e garantir o meio ambiente de trabalho saudável para esses trabalhadores, pois para ambos o objeto, a tutela e o propósito são os mesmos. Cada um a seu modo, o primeiro com o uso do conhecimento popular, o segundo com a utilização do conhecimento científico e técnico, buscarão efetivar o meio ambiente de trabalho sadio. Não se faz necessário ter os 
mesmos pressupostos basilares. O conhecimento popular é valorativo por excelência e se fundamenta essencialmente em estados de ânimo e emoções, enquanto o conhecimento científico é tido como o conhecimento real ou factual. Ambos se distanciam em seus fundamentos, mas se reaproximam no mais importante, a preocupação com o meio ambiente de trabalho. Por certo, cada um a seu modo, tentará efetivar um meio ambiente de trabalho salubre. Pescadores artesanais e marisqueiras de Ilha de Maré fazem uso da oralidade, conversam entre si, discutem com instituições, empresas, com a sociedade, cobram dos entes federativos a responsabilidade pela poluição da fauna e flora de Maré. O Direito Ambiental do trabalho, por sua vez, ao ser invocado faz uso de seus princípios, de normas já estabelecidas no Direito Brasileiro com o intuito de responsabilizar todos os que contribuíram para a contaminação ambiental em Maré (CARVALHO, 2013, p. 196).

Inobstante, o Direito Ambiental do Trabalho, como defendido por Carvalho (2013) e CARVALHO et alii, 2014, apresenta as mesmas premissas e princípios oriundos do direito ambiental e, portanto, do direito pós-moderno. Dessa forma, como de fato efetivar, garantir, promover o direito ao meio ambiente natural e laboral saudável, equilibrado e sustentável de Comunidades Tradicionais como a de Maré? Como defender Maré quanto aos conflitos sócios ambientais vivenciados in loco?

Propõe-se aqui que a solução esteja ainda no Direito Ambiental do Trabalho. Explicitase, não na forma como defendida anteriormente (CARVALHO, 2013; CARVALHO et alii, 2014), mas no Direito Ambiental do Trabalho que tenha por fundamento a perspectiva do pluralismo jurídico pós-moderno, ou seja, que emancipa ou que possibilita a emancipação do direito consuetudinário em comunidades tradicionais como a de Maré, sendo respeitado pelo Estado de direito oficial brasileiro.

Defende-se um Direito Ambiental do Trabalho cujo nascedouro seja a "crítica jurídica a ciência neomoderna" aparentemente rendida aos ditames do sistema econômico capitalista do século XXI, ao direito monopolizador, ao estado de direito que permite a pilhagem, exploração e marginalização de grupos vulneráveis, a monocultura. Argumenta-se, pela possibilidade de adoção de um Direito Ambiental do Trabalho advindo de uma conjuntura de inquietudes, resistências, rupturas, paradigmático, de caráter interdisciplinar, que permita a construção epistemologica e metodologicamente, de um direito consuetudinário alternativo, de reação sociológica e de cunho antropológico, frente à ciência jurídica tradicional, aproveitando-se do tratamento que seria conferido na práxis e implementado sob o fundamento do novo pluralismo jurídico.

Verificou-se que não bastaria ser um Direito Ambiental do Trabalho, que busca promover o meio ambiente natural e laboral sadio para pescadores artesanais e marisqueiras inseridas nesse meio e, sim, um direito ambiental do trabalho que se correlaciona e corresponde 
ao novo paradigma do pluralismo jurídico, "transpondo as modalidades de cultura sociopolítica identificadas pelo convencionalismo dos pluralismos orgânico e corporativos, neoliberal capitalista transnacionais e globalizados" como defendido por Wolkmer (2019, p. 2729). Ressaltou-se que o Direito Ambiental do Trabalho que não vai ao encontro aos princípios, regras e objetivos das Comunidades Tradicionais no Brasil é aquele que concede autonomia e participação direta e efetiva para as Comunidades, quando da elaboração das normas jurídicas oficiais produzidas pelo Estado de direito brasileiro, quando, além disso, as Comunidades Tradicionais são tratadas como sujeitos/objetos de políticas públicas apropriadas às Comunidades Tradicionais, pelos chefes de governo nas diversas esferas, suas secretarias e ministros, partindo-se da premissa de uma hipossuficiência econômica, social, histórica, cultural e jurídica, que concede o devido reconhecimento e espaço privilegiado para as Comunidades Tradicionais e, por fim, quando do exercício da função judiciária pelo Estadojuiz, quando de julgamentos que envolvam Comunidades Tradicionais em conflitos socioambientais no Brasil, tendo-se por base a necessidade de equilibrar a balança do direito, que hoje se encontra em desfavor das Comunidades Tradicionais no Brasil.

\section{Conclusão}

Evidencia-se que o direito estatal oficial que impera no Brasil, enquanto monocultura jurídica do Estado brasileiro que regula tudo e todos, atrelado à economia neocapitalista globalizada tecnológica e dominante, não tem permitido que Comunidades Tradicionais consigam sagrar-se como vencedoras nos inúmeros conflitos sócio ambientais que vivenciam, ou mesmo, como exitosas na reparação dos danos ambientais ocasionados nos seus territórios e/ou nos seus entornos, como é o caso de Maré, isso devido à lógica da ordem econômica, política, social, histórica e cultural, a que foi submetida a Ilha de Maré e seus moradores, e que se contrapõem diametralmente aos princípios, regras, necessidades, interesses e objetivos das Comunidades Tradicionais brasileiras.

Conclui-se que, na práxis, a Comunidade Tradicional Quilombola e Pesqueira de Maré está inserta em um Estado de opressão e invisibilidade, que não só permite, como também incentiva a exploração do ecossistema natural onde residem Comunidades Tradicionais, a marginalização do modo de vida da pesca artesã e da mariscagem, que não têm como premissas o acúmulo de riquezas, ou mesmo, o consumo acelerado, como também a subserviência dos direitos consuetudinários das Comunidades Tradicionais à normativa oficial estatal do direito 
neoliberal globalizado, que busca tornar imperceptíveis os conflitos socioambientais por quais passam as Comunidades Tradicionais, como ocorre com Maré.

Por fim, acredita-se que somente o Direito Ambiental do Trabalho, advindo de uma perspectiva e adoção do novo pluralismo jurídico, de cunho antropológico, de reação à ciência monojurídica tradicional, que adere a um caráter interdisciplinar do direito, que permite e difunde o aceite e a aplicabilidade inconteste do direito consuetudinário alternativo, poderá romper com o desequilíbrio da balança no direito para as Comunidades Tradicionais no Brasil.

\section{REFERÊNCIAS}

ANDRADE, O. A. A disputa pela diversidade jurídica nos tempos da globalização neoliberal. A propósito, poderá o direito ser emancipatório? Revista Direito e Práxis, v. 6, n. 1, 2015. Disponível em: https://www.epublicacoes.uerj.br/index.php/revistaceaju/article/view/15403/11728. Acesso em: 22 mar. 2021.

ARDILA AMAYA, E. Pluralismo Jurídico: apuntes para el debate. El Otro Derecho, n. 2627, Ilsa, Bogotá, 2002.

BARRETO, I. G. S.; MARTINS, D. V.; VIDAL, J. da P. Posibilidad de coexistencia simultánea de órdenes legales diferentes y/o diametralmente opuestos en la misma comunidad debido a la omisión del estado o debido a la resistencia cultural. Revista de Direito Público, Brasília, (no prelo) 2021.

BRASIL. Presidência da República. Decreto n. ${ }^{\circ}$ 6.040, de 7 de fevereiro de 2007. Diário Oficial da União, 8 fev. 2007.

BOURDIEU, P. Poder, derecho y clases sociales. Trad. Ma. José González Ordovás. Bilbao: Desclée, 2001.

BOURDIEU, P. "Los juristas, los guardianes de la hipocresía colectiva”. Trad. J. R. Capella, Jueces para la democracia, 2003, 47, 3-5.

BOURDIEU, P. Intelectuales, política y poder. Trad. Alicia Gutiérrez. Buenos Aires: EUDEBA, 2007.

CAPUCCI, M. R. Aspectos fundiários das comunidades caiçaras. In: STANICH NETO, P (Org.). Direito das Comunidades Tradicionais Caiçaras. São Paulo: Café com Lei, 2016.

CAROSO, C.; TAVARES, F.; PEREIRA, C. (Orgs.). Baía de Todos os Santos: Aspectos Humanos. Salvador: EDUFBA, 2011.

CARVALHO, I. G. S. A percepção da marisqueira sobre o seu direito a um meio ambiente de trabalho saudável e as normas do direito ambiental do trabalho brasileiro, 2013. Dissertação (Mestrado em Saúde, Ambiente e Trabalho) - Faculdade de Medicina da Bahia, Universidade Federal da Bahia, Salvador, 2013.

CARVALHO, I. G. S. et alii. Por um diálogo de saberes entre pescadores artesanais, marisqueiras e o direito ambiental do trabalho. Ciências e saúde coletiva, Rio de Janeiro, v. 19, n. 10, p. 4011-4022, Oct. 2014. Available from <http://www.scielo.br/scielo.php?script=sci_arttext\&pid=S1413- 
CARVAlHO, I. G. S. Pesca artesanal na Baía de Todos os Santos: um reduto do trabalho informal no Brasil. In.: SILVA, A. de J. S. e. Ensaios de Direito Sul-Americano. São Paulo: Max Limonad, 2019, p. 125-138.

CARVALHO, I. G. S. Diálogos entre a percepção da marisqueira e do pescador artesanal de Ilha de Maré e o Direito Ambiental do Trabalho sobre o Direito desses a um meio ambiente de trabalho saudável. In.: MARQUES, M.; DUARTE, A. A. A. R. Temas de Direito Público e Privado: Estudos em homenagem ao VIII centenário da Universidade de Salamanca. Rio de janeiro: Lumen Juris, 2019, p. 215-248.

CHAGAS, M. de F. A do reconhecimento da política dos "remanescentes das comunidades dos quilombos". Horiz. antropol., Porto Alegre, v. 7, n. 15, pág. 209-235, julho de 2001. Disponível em <http://www.scielo.br/scielo.php?script=sci_arttext\&pid=S010471832001000100009\&lng=en\&nrm=iso >. Acesso em: 22 mar. 2021. https://doi.org/10.1590/S0104-71832001000100009.

CHAMY, P. Reservas Extrativistas Marinhas como instrumento de reconhecimento do direito consuetudinário de pescadores artesanais brasileiros sobre territórios de uso comum. In: The commons in an age of global transition: challenges, risks and opportunities, the tenth Conference of the International Association for the Study of Common Property. Oaxaca, Mexico, Aug. 9-13, 2004.

DIDIER JÚNIOR, F. Curso de direito processual civil - v. 1: Introdução ao direito processual civil, parte geral e processo de conhecimento. 21. ed. Salvador: JusPODIVM, 2019.

DWORKIN, R. Levando os direitos a sério. São Paulo: Martins Fontes, 2002.

FREITAS, M. do C. S. Un ambiente enfermo: significados de la contaminación industrial en Isla de Maré, Bahía, Brasil. Desacatos, Cidade do México, n. 39, p. 73-88, 2012.

FUCHS, K. M. Estudo epidemiológico de queixas relacionadas à rinite em marisqueiras da Ilha de Maré. Monografia (Conclusão de Curso) Universidade Federal da Bahia, Faculdade de Medicina, Salvador, 2013.

HATJE, V.; BÍCEGO, M. C.; CARVALHO, G. C. de; ANDRADE, J. B. de. Contaminação Química. In: HATJE, V.; ANDRADE, J. B. de. (Orgs.). Baía de Todos os Santos: Aspectos Oceanográficos. Salvador: EDUFBA, 2009.

HATJE, V.; ANDRADE, J. B. de. (Orgs.). Baía de Todos os Santos: Aspectos Oceanográficos. Salvador: EDUFBA, 2009.

HATJE, V.; ATTISANO, K. K.; SOUZA, M. F. L. de; MAZZILLI, B; OLIVEIRA, J. de; M., T. de A.; BURNETT, W. C.. Applications of radon and radium isotopes to determine submarine groundwater discharge and flushing times in Todos os Santos Bay, Brazil. Journal of Environmental Radioactivity , v. 178-179, p. 136-146, 2017.

HATJE, V.; ANDRADE, R. L. B.; JESUS, R.M.; MASQUÉ, P. ; ALBERGARIA-BARBOSA, A.C.R.; DE ANDRADE, J. B. ; SANTOS, A. C. S. S. . Historical records of mercury deposition in dated sediment cores reveal the impacts of the legacy and present-day human activities in Todos os Santos Bay, Northeast Brazil. Marine Pollution Bulletin, v. 145, p. 396-406, 2019.

LIS/ICICT/FIOCRUZ. Mapas de conflitos envolvendo injustiça ambiental e saúde no Brasil. Ilha de Maré. Disponível em: 
$<$ http://www.conflitoambiental.icict.fiocruz.br/index.php?pag=ficha\&cod=38>. Acesso $14 \mathrm{de}$ julho de 2020.

MARCONDES, D.; RAIMUNDO, S. Povos tradicionais e turismo: o taus como instrumento para gestão de conflitos? Ambient. soc., São Paulo, v. 22, 2019.

MARTINS, J. de S. As novas culturas dos pobres do campo. In: MARTINS, José de Souza. Caminhada no chão da noite: emancipação política e libertação nos movimentos sociais no campo. São Paulo: Hucitec, 1989.

MINAYO, M. C. S. Pesquisa social: teoria, método e criatividade. Rio de Janeiro: Vozes, 1994.

NICOLAU JÚNIOR, M. Segurança jurídica e certeza do direito: realidade ou utopia num Estado democrático de direito? Universo Jurídico, Ano XI, Juiz de Fora, 2004.

OLIVEIRA, L. R. C. de. A dimensão simbólica dos direitos e a análise de conflitos. Revista de Antropologia: São Paulo, USP, v.53, nº 2, 2010.

OLIVEIRA, L. R. C. Da moralidade à eticidade, via questões de legitimidade e equidade, In.: R. Cardoso de Oliveira e L. R. Cardoso de Oliveira. Ensaios Antropológicos sobre Moral e Ética. Rio de Janeiro: Tempo Brasileiro. Biblioteca Tempo Universitário 99, 1996.

OLIVEIRA, L. R. C. Concepções de Igualdade e (des)igualdade no Brasil, em LIMA, R. K. de; EILBAUM, L; PIRES, L (Org.). Conflitos, Direitos e Moralidades em perspectiva comparada - volume 1. Rio de Janeiro: Garamond, 2010.

PENA, P. G. L.; GOMEZ, C. M. Saúde dos pescadores artesanais e desafios para a Vigilância em Saúde do Trabalhador. Ciênc. saúde coletiva, Rio de Janeiro, v. 19, n. 12, p. 4689-4698, dez. 2014. Disponível em <http://www.scielo.br/scielo.php?script=sci_arttext\&pid=S1413$81232014001204689 \& \operatorname{lng}=$ pt\&nrm=iso>.

acessos em 06 July 2020. https://doi.org/10.1590/1413-812320141912.13162014.

PENA, P. G. L.; FREITAS, M. do C. S. de; CARDIM, A. Trabalho artesanal, cadências infernais e lesões por esforços repetitivos: estudo de caso em uma comunidade de mariscadeiras na Ilha de Maré, Bahia. Ciênc. saúde coletiva, Rio de Janeiro, v. 16, n. 8, p. 33833392, Aug. 2011. Available from $<$ http://www.scielo.br/scielo.php?script=sci_arttext\&pid=S1413-

$81232011000900005 \& \operatorname{lng}=\mathrm{en} \& \mathrm{nrm}=\mathrm{iso}>$.

access on 06 July 2020. https://doi.org/10.1590/S1413-81232011000900005.

PENA, P. G. L.; MARTINS, V.; REGO, R. F. Por uma política para a saúde do trabalhador não assalariado: o caso dos pescadores artesanais e das marisqueiras. Rev. bras. saúde ocup., São Paulo , v. 38, n. 127, p. 57-68, June 2013 . Available from $<$ http://www.scielo.br/scielo.php?script=sci_arttext\&pid=S0303-

$76572013000100009 \& \operatorname{lng}=\mathrm{en} \& \mathrm{nrm}=\mathrm{iso}>$.

access on 06 July 2020. https://doi.org/10.1590/S0303-76572013000100009.

PENA, P. G. L.; NORTHCROSS, A. L.; ANGELIM, M.; RÊGO, R. C. F. Derramamento de óleo bruto na costa brasileira em 2019: emergência em saúde pública em questão. Cadernos de Saúde Pública, v. 36, p. 1-5, 2020.

PORTO, M. F.; PACHECO, T.; LEROY, J. P. (Eds.) Injustiça Ambiental e Saúde no Brasil: o Mapa de Conflitos. Rio de Janeiro: Fiocruz, 2013. 
REGO, R. F. et alii. Vigilância em saúde do trabalhador da pesca artesanal na Baía de Todos os Santos: da invisibilidade à proposição de políticas públicas para o Sistema Único de Saúde (SUS). Revista Brasileira de Saúde Ocupacional, São Paulo, v. 43, supl. 1, e10s, 2018.

RIOS, K. A, N. O ser pescador(a) artesanal e o território articulado das comunidades tradicionais pesqueiras da Ilha de Maré - Bahia. Mares: Revista de Geografia e $\begin{array}{lllllll}\text { Etnociências, v. } & 2, & \text { n.1, } & \text { p. } & 7-18 . & 2020 & \text { Disponível em: }\end{array}$ http://revistamares.com.br/index.php/files/article/view/46. Acesso em: 22 mar. 2021.

ROCHA, J. C. de S. da. Direito ambiental e meio ambiente do trabalho: dano, prevenção e proteção jurídica. São Paulo: LTr, 1997.

ROCHA, J. C. de S. da. Direito Ambiental do Trabalho. São Paulo: LTr, 2002.

ROCHA, J. C. de S. da.; KHOURY, L. E. C.; NASCIMENTO, A. P. D. Direito das águas trajetória legal, conflitos e participação social. Revista de Direito Sanitário, v. 18, p. 143-166, 2018.

ROCHA, J. C. de S. da.; NERI, R. Novos ecologismos: por uma lógica ambiental contrahegemônica - tributo a Ordep Serra. Revista Brasileira de Direito Animal, v. 13, p. 61-82, 2018.

SALES, I. G.; RÊGO, R. de C. F; PENA, G. L. P. Direito Ambiental do Trabalho e o meio ambiente de trabalho saudável. In.: SILVA, A. de J. S. e. Questões ambientais em Saúde Coletiva. EDUFMT, Cuiabá, 2012, p. 115-146.

SALES, I G; VIDAL, J. da P. A comunidade tradicional quilombola de pescadores artesanais e marisqueiras da Ilha da Maré, no Brasil, e sua exclusão social, histórica e cultural: um processo de invisibilidade. Revista Interdisciplinar em Educação e Territorialidade RIET, [S.1.], v. 1, n. 1, p. 48-70, dez. 2020. ISSN 2676-0355. Disponível em: <https://ojs.ufgd.edu.br/index.php/riet/article/view/12955>. Acesso em: 22 mar. 2021. doi:https://doi.org/10.30612/riet.v1i1.12955.

SANTOS, B. de S. O discurso e o poder: ensaio sobre a sociologia da retórica jurídica. Porto Alegre: Sergio Antonio Fabris, 1988.

SANTOS, B. de S. A crítica da razão indolente contra o desperdício da experiência: para um novo senso comum: a ciência, o direito e a política na transição paradigmática. vol 1. São Paulo: Cortez, 2013.

SANTOS, B. de S. Sociología jurídica crítica. Para un nuevo sentido común del derecho. Trad. Elvira del Pozo Aviñó. Madrid: Trotta / Instituto Latinoamericano de Servicios Legales Alternativos, 2009.

SILVA, D. "Toxic Tour" com Boaventura de Souza Santos denuncia poluição em Ilha de Maré. Forum Social Mundial, 20 mar. 2018. Disponível em: 〈https://bit.ly/2AZdB6E >. Acesso em: 11 ago. 2019.

TREVIZAN, S. D. P.; LEAO, B. M. Pluralidade jurídica: sua importância para a sustentabilidade ambiental em comunidades tradicionais. Soc. estado., Brasília, v. 29, n. 2, p. 539-560, ago. 2014.

VIEIRA, J. C. Direito consuetudinário: distinções e implicações no campo jurídico. XV Congresso Nacional do Conpedi, 2006, Manaus. Anais do XV Congresso do Conpedi, v. 1. São Paulo: Conpedi, 2006, p. 1-14. 
YIN, K. R. Estudo de caso: planejamento e métodos. 4ª ed. Bookman, 2010.

ZIBECHI, R. Descolonizar el pensamiento crítico y las prácticas emancipatórias. Bogotá: Desde Abajo, 2015.

WOLKMER, A. C. Pluralismo Jurídico: um referencial epistêmico e metodológico na insurgência das teorias críticas no direito. Revista Direito e Praxis, v. 10, no 4, 2019, p. 27112735. 